\title{
Efficiency of marketing communications in banks
}

\author{
Tetyana Pimonenko
}

Ph.D., Senior Lecturer, Economics and Business Administration Department, Sumy State University, Ukraine

\section{Oleg Radchenko}

Ph.D., Head of Sumy Regional Branch of JSC “Oschadbank”, Ukraine

\section{Maksim Palienko}

Ph.D., University of Insurbia, Como, Italy

\begin{abstract}
The paper deals with analysing the main approaches to evaluate the quality and efficiency of the bank's marketing communications. The approaches to define the bank's marketing communications were analysed and systematized by the authors. Besides, the authors allocated the main features of the bank's marketing communications in the ongoing Ukrainian economic situation. Moreover, they proposed to use the mathematical method, to identify the efficiency of the bank's marketing communications. According to that method the efficiency of the bank's marketing communications could be determined through the evaluation of the increasing volume of the services rendered by the bank. This method gives an opportunity to account the time lag between implementation of the bank's marketing communications and starting of its action. With purpose to verify abovementioned approach, the authors calculated the efficiency of the bank's marketing communications of the JSC "Oschadbank" (Sumy, Ukraine).
\end{abstract}

Keywords: bank, communication, efficiency, marketing, motivation.

JEL Classification: G21, M3, B23, C02.

DOI: $10.21272 /$ bel.1(2).55-61.2017.

(C) The Authors, 2017. This article is published with open access at ARMG Publishing.

\section{Introduction}

The ongoing economic situation and snowballing changes at the banking market contribute the implementation and using the modern and effective instruments to promote their services and products at the market. Unfortunately, Ukrainian economic situation is not stable and the market conditions change very often and quickly. From the other side, the proposition at the banking market is increasing from day to day. As a consequence, the banks have to concentrate own forces on the implementation of effective marketing instruments with purpose to promote their services. Should underlined that correct marketing instruments allowing to:

- decrease the gap between bank and customers;

- decrease the clients' distrust;

- increase the bank's image;

- stimulate sales and etc.

That is why it is necessary to provide the system of management of banks' marketing communications with purpose to maximize and receive the synergetic effect from the using of the different instruments on the complex base. In this regard, we should understand how to evaluate the management system of the banks' marketing communications.

\section{Literature review}

The results of analyses showed that many economists have already investigated the questions connected with marketing communications, but the suitable meaning of marketing communications is defined yet. Thus, in modern economic literature you can find the following definitions: "marketing communication", "complex of marketing communication", "communication policy". 
According to the Association of American Advertising Agencies [1], marketing communications are a strategic planning basing on the optimal combination of different marketing communications with purpose to maximize marketing programs with elimination of incompatible communications. On the contrary, Micael Dahlen [5; 12] identified marketing communications as a process of information sharing between the market participants. According to another approach $[11 ; 16]$, marketing communications are a complex of elements, which transmitted between the market participants. And the fourth group of scientists analysed the marketing communications as the complex of methods.

As the results, we can summarise that in the wide sense, the bank's marketing communications are the system of collaborations between clients and bank according to the market situation making connection with client base and maximise the collaboration effect. In the strict sense, the bank's marketing communications can be defined as a planning complex of activities to create the stable client base and to stimulate selling. This complex of activities should be realised according to a current budget through the mutually agreed mechanism of the bank's marketing communications.

It should be underlined, a great number of scientific manuscripts is devoted to the problem of evaluating the efficiency of bank's marketing communications. The following scientists investigated this question in own works: F. Kotler [10], S. Illyashenko [7; 8], P. Copley [4], R. Reidenbach, D. Moat, R. Pitts [22; 23] and etc.

According to them, we can identify two main approaches to evaluate the marketing communications: quantitative and qualitative methods. Evidently, that the use of approaches and instruments depend on the target audience.

Despite the huge number of investigations and publications in this sphere, the applied approaches to evaluate the efficiency of management system of the bank's marketing communications are non-developed. The main goal of this paper is to analyse the current literature in this sphere, identify how to account the time factors and seasonal fluctuation in demand on the bank's services. In addition, allocate the main forces to stimulate the bank's front-managers to increase the efficiency of the bank's marketing communications.

\section{Methodology}

According to the paper's aim, the following questions are analysed: the main approaches to define the bank's marketing communications; allocate the key factors and indicators which influence on the bank's marketing communications efficiency and possible ways to stimulate the front-managers. Then, according to the results of analysed and mathematical tool, the authors formulated the approaches to evaluate the efficiency of the bank's marketing communications. The last stage is verifying proposed approaches.

For this purpose, the authors use the related economic literature, official finance date from the JSC "Oschadbank" (Sumy, Ukraine). Correlation, regression and factor analysis are used by the authors to identify the influences' factors on the efficiency of bank's marketing communications.

\section{Results of research}

According to the abovementioned, the management of efficiency plays the key role in the system management of the bank's marketing communications. First of all, it allows to compare the financial results from the use of marketing communications with the expenses for them. In addition, we can compare our results with previous activities and adopt the bank's current and strategy plans. Moreover, the results of efficiency allowing to create the correct and corresponding motivation system for the bank's staff.

It should be underlined at traditional approaches to evaluate the efficiency of the bank's marketing communications are based on the quantitative method, such as: factor analysis of bank's financial standing before and after implementation of the bank's marketing communications. According to this method, we can estimate the influence of each factor on the bank's profit. However, using this approach cannot be estimate the quality of the current management system of the bank's marketing communications and evaluate the synergy effect of the marketing communications collaborations.

The results of analysing allowing to systematize the additional factors which influence on the efficiency of the bank's marketing communications. Thus, along with traditional we propose to consider the following factors: time factor, season fluctuation at the banking market, deferred demand and additional effect from the previous marketing communications. 
Traditionally the effect of the marketing communications is identified by the increasing of the bank assets or volume of clients. These approaches can't take account of two main features: how many clients have reacted on the bank's marketing communications; considering only new clients we eliminated the old clients' reaction.

That is why we propose to use formula 1 to analyse the increasing volume of the services rendered by the whole bank.

$S=S_{p}+S_{\Delta t}-S_{r} \pm \operatorname{Sin}$,

where $S$ - effect from the marketing communications; $S_{p}$ - current effect from the using of the bank's marketing communications; $S_{\Delta t}$ - effect from deferred demand (starting to appear effect with time lag $\Delta t$ after the spontaneous using of the bank's marketing communications have been finished; $S_{r}$ - transformation effect (effect from the previous using of the bank's marketing communications which haven't been taken account in the analysing period yet; Sin - increment effect from increasing of services which provided by the bank during the seasonal fluctuations.

According to this, we propose two assumptions:

Assumption 1. Effect appears immediately after the bank's marketing communications have been activated. Noticed, that the costs for the marketing communications spend at the beginning of the month. However, the number of clients is the results of the whole month and we take to account the result at ending of month.

Assumption 2. We have the time lag between the using of the bank's marketing communications and the effect appearing. This process we can name as effect of the deferred demand.

The first assumption we can verify through the researching of the market reaction. We calculate the correlation between changes of the bank's expenses on the marketing communications and the volume of the services rendered for the same period. The second assumption can be verified through the calculation the autocorrelation coefficient.

With purpose to confirm the abovementioned assumptions we verify them on the Ukrainian bank JSC "Oschadbank" (the branch in Sumy). In our research we analysed the influence of the total cost to the marketing communications on the temp of increasing the client base.

According to the bank's internal documentations, the following expenditure items are:

- media advertising expenditure;

- expenditure for the design of the promotional materials;

- expenditure for the publishing the advertising materials;

- expenditure for the external advertising;

- expenditure for the sustaining the brand image.

The graphs interpretation of received results (Figure 1, see in Appendix) allows to make conclusion that one month is the minimal time lag between the start of implementation of marketing communications and their active action. Such results can be explained through the high client's confidence level to the bank during the non-stable country's situation.

During the crises in 2008-2009 years, the level of client's confidence increased in the short-term period. However, from Figure 1 we saw that results of 2008-2009 are distorted. That is why we eliminate the results of 2008-2009 years and analyse the results after 2009 year. The results of analysing are showed on Figure 2 (see in Appendix).

According to results, we can make conclusion that in average the changes of the costs from the diapason between 250 to $1000 \mathrm{UAH}$ provide the changes of the increment of the client base from $-0.11 \%$ to $0.22 \%$.

Considering that the first assumption is not approved, we suppose that the time lag between the realising process and reaction bank's marketing communications is taken place. To verify this assumption we identify the autocorrelation coefficient $(K V)$ between total costs and increment of the selling volume under the condition of gradual displacement of the last parameters (Table 1). If $K V>0.7$, the assumption will be disproved. On the contrary, if $K V<0.7$, the assumption will be approved. 
Table 1. Coefficient of autocorrelation between total costs and increment of the client base

\begin{tabular}{|c|c|c|c|c|c|c|c|c|c|c|c|c|c|}
\hline & \multicolumn{13}{|c|}{ Period of time lag between costs for marketing communications and increment of the client base, month } \\
\hline & 0 & 1 & 2 & 3 & 4 & 5 & 6 & 7 & 8 & 9 & 10 & 11 & 12 \\
\hline KV & -0.55 & 0.73 & -0.06 & -0.09 & -0.09 & -0.01 & -0.23 & 0.02 & 0.03 & -0.05 & 0.06 & 0.02 & -0.02 \\
\hline
\end{tabular}

According to results in Table 1, we can make conclusion that assumption 2 is approved by the calculations. We can identify that the partial time lag in one month (after marketing communications have been implemented) is taken place. It should be noticed that this effect will appear if we continuously increase the massive dates of the increment of the client base. In other case, the coefficient of autocorrelation is in the diapason from 0.01 to 0.55 which approved the lack dependence between the parameters.

In our research we propose to use the dynamic mathematical model to estimate the transformation effect. For this purpose, we propose the following parameters, assumptions and conditions:

$t=1, \ldots, T-$ time index is discrete. It means that input dates measured in the discrete intervals.

At any time $(i=1, \ldots, \mathrm{I})$ the client can make decision to buy products or service $a_{\mathrm{i} t}$.

Vector of state $S_{r}$ depends on the parameters (level of competition at the market, efficiency of the market communications and etc.) which influenced on the last customer's decision to buy the bank's product. This approach allowing to eliminate the main disadvantage of the static data.

Using the mathematical approach of A. Makarova "dynamics of probabilities" [24], the effect of marketing communications with considering time lag can be valued as follows:

$S_{r(t+1)}: f\left(\cdot \mid S_{r t}, a_{\mathrm{i} t}\right)$

$U\left(S_{r t}, a_{\mathrm{i} t}\right)$ - current compensation which customers can receive in a certain period of time $(t+1)$, due to action $a_{i t}$.

With assumption that client's behaviour is rational and he makes decision with purpose to maximize the net present value and delaying a decision to buy can be explained by his desire to receive the discount in the future in the additional profit $S_{\Delta t} \epsilon(0,1)$. Noticed, the coefficient of discounting is $0\left(S_{\Delta t}=0\right)$. Thus, the transformation period does not exist. To investigate the effect of transformation period from marketing communications, we analyse the cases if $S_{\Delta t}>0$.

Considering the abovementioned assumptions and parameters, the effect of the transformation period can be calculated as follows:

$S_{r}=\underset{a_{i t} \in\{1, \ldots, J\}}{\operatorname{argmax}}\left\{U_{i}\left(S_{r t} ; a_{i t}, a_{-i t}\right)+S_{\Delta t} E\left[V_{i}\left(S_{t+1}\right) \mid S_{t} ; a_{i t}, a_{-i t}\right]\right\}$

The main goal is to determine the maximum point, that argument functions, which reached a maximum value of the transition effect.

In this case we use the traditional approach to calculate the standard dispersion:

$\partial=\sqrt{\sum_{\mathrm{i}=0}^{\mathrm{n}}\left(\mathrm{x}_{\mathrm{i}}-\mathrm{M}(\mathrm{x})\right)} \mathrm{p}_{\mathrm{i}}^{2}$

where $\mathrm{x}_{\mathrm{i}}-i$ sample unit; $\mathrm{p}_{\mathrm{i}}-$ event rate $i$ action; $\mathrm{M}(\mathrm{x})$ - mathematical expectation of particular action.

The main problem in creating the evaluation model is the difficulty in allocating the reasons of changes. Therefore, we propose to use the following system of linear equations:

$\left\{\begin{aligned} S_{t} & =S_{p t}-\operatorname{Sin}_{t} \\ S_{p t} & =f\left(x_{i}\right)+\partial_{S p} \\ \operatorname{Sin}_{t} & =f\left(y_{i}\right)+\partial_{\text {Sin }}\end{aligned}\right.$

where $S_{t}$ - the result of growth in sales of banking services; $S_{p t}$ - increase in sales of banking services under the influence of marketing communications; $\operatorname{Sin}_{t}$ - increase in sales of banking services under the influence of other reasons; $x_{i}, \mathrm{y}_{i}$ - specifying a set of variables (factors influence on the sales); $\partial_{S p}, \partial_{S i n}$ - the deviation of the growth rate of sales of banking services. 
The results of analysing the function of the banking market showed that main parameter is the season fluctuation. Therefore, we can analyse the correlation between the season fluctuation and the selling volume. For this purpose, we propose to use algorithm based on the Person's method [9].

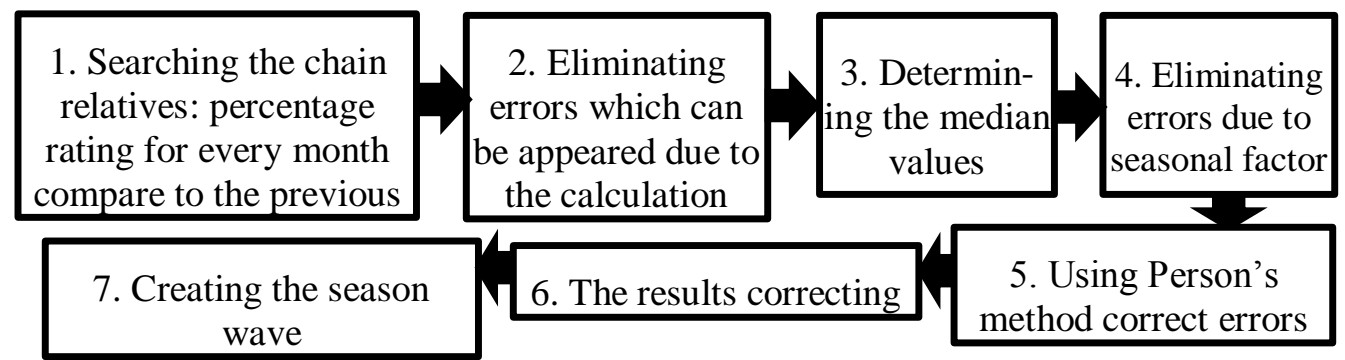

Figure 3. The algorithm to determine the seasonal fluctuation of changes in the selling volume of the bank's services

Source: bases on the Person's method [9].

According to the abovementioned approach, we can allocate the dependent and independent variables. Thus, independent variable - the results of selling increasing at the bank. The dependent variables are time of acting the marketing communication; maximum number of the clients; maximum limit of the bank's financial resources, which can be spent to the marketing communications; bonus program, special discount program that can be provided by the bank.

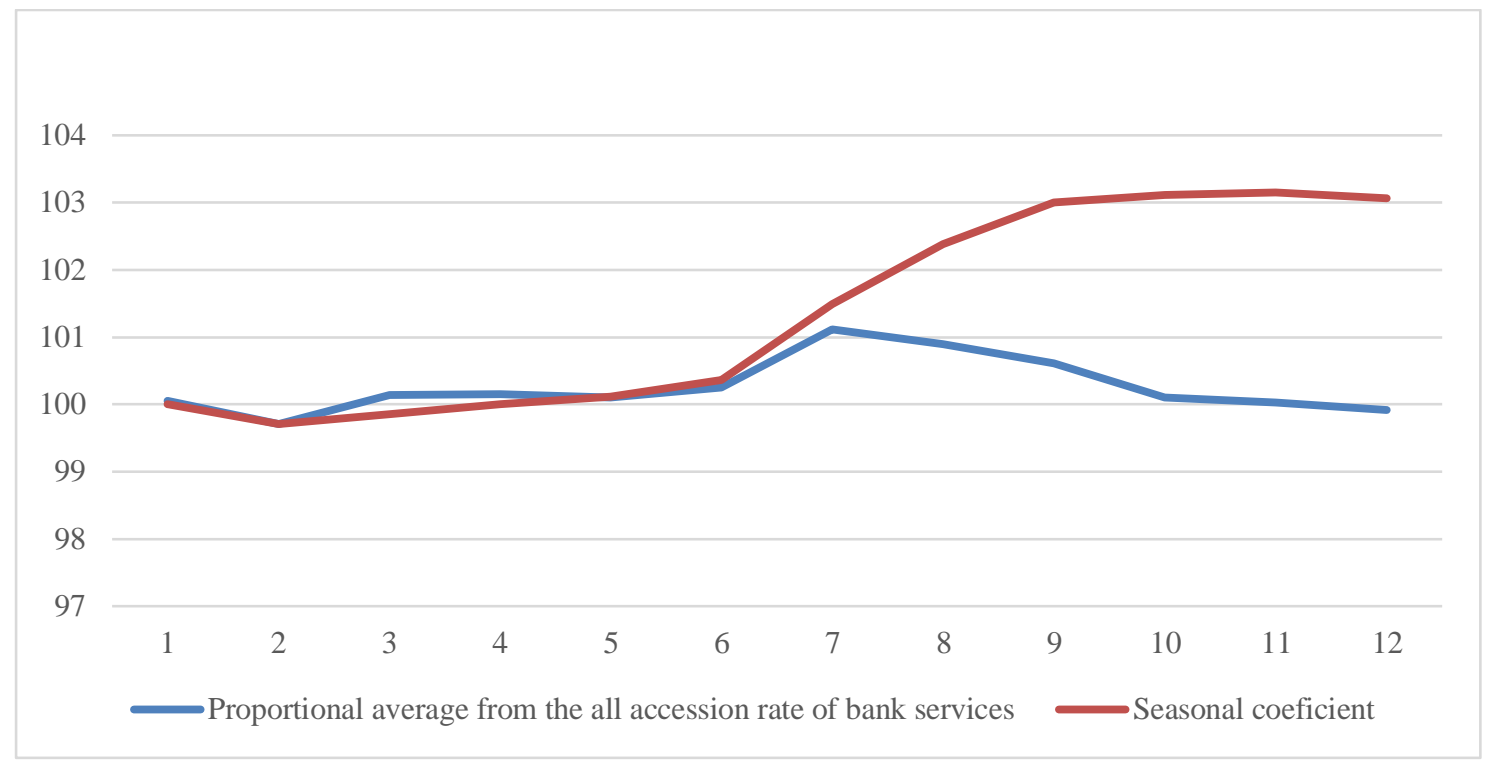

Figure 4. The monthly coefficient of seasonal fluctuation of services rendered by bank on the example of JSC "Oschadbank" (Sumy, Ukraine)

The results of calculation are shown in Figure 4. According to these results, we can suggest that the use of marketing communication has a positive influence on bank efficiency.

\section{Conclusions}

In conclusion, the results of research showed that determination of the additional effect from the bank's marketing implementation is the basis for identification the maximum level of the client base increasing due to implantation of bank's communication policy. In addition, it gives opportunity to estimate the profitability of the future costs to bank's marketing communications.

\section{References}

1. 4A's - Association of American Advertising Agencies. Retrieved from http://www.aaaa.org/Pages/default.aspx.

2. Belch, G.E., Belch, M.A., Kerr, G.F., \& Powell, I. (2014). Advertising: An integrated marketing communication perspective. McGraw-Hill Education. 
3. Chen, Y., Xie, J. (2008). Online consumer review: Word-of-mouth as a new element of marketing communication mix. Management science, 54(3), 477-491.

4. Copley, P. (2004). Marketing communications management: concepts, theories, cases and practices. Jordan Hill, Oxford, 435 p.

5. Dahlen, M., Lagne, F., Smith T. (2010). Marketing Communications: a brand narrative approach. Chichester, UK: John Wiley \& Sons Ltd., $571 \mathrm{p}$.

6. Finne, Å., Finne, Å., Grönroos, C., \& Grönroos, C. (2017). Communication-in-use: customer-integrated marketing communication. European Journal of Marketing, 51(3), 445-463.

7. Illyashenko, S. (2011). The problems and perspectives of the market oriented management of innovation development. Sumy: Papirus, $644 \mathrm{p}$.

8. Illyashenko, S. (2012). Marketing at the company. Economics of Enterprises. Sumy: University Book, pp. 528-559.

9. Ivchenko, G., Dedvedev, J. (1984). Mathemetical statistics. Moscow: High Shool, 248 p.

10. Kotler, F. (2005). Marketing Management. Petersburg: Science, 896 p.

11. Lambin, J. (1996). Strategic marketing. European perspectives. Petersburg: Science, 800 p.

12. Miller, D. (2008). Retail Marketing - A Branding and Innovation Approach. Tilde University Press, Melbourne, $137 \mathrm{p}$.

13. Montgomery, D., Silk, A. (1972.) Estimating Dynamic Effects of Marketing Communications Expenditures. Management Science, 18(10), 485-501.

14. Muthukrishnan, S., Pal, M., Svitkina, Z. (2010). Stochastic Models for Budget Optimization in SearchBased Advertising. Algoritmica, 58, 1022-1044.

15. Naik, P., Raman, K. (2003). Understanding the Impact of Synergy in Multimedia Communications. Journal of Marketing Research (JMR), 40(4), 375-388.

16. Noritsyna, N. (2003). Marketing communication policy: lectures. Kyiv, 320 p.

17. Online advertising effectiveness. Retrieved from http://www.comscore.com/.

18. Outdoor: Special Advertising Journal. Retrieved from http://outdoor.ru/

19. PricewaterhouseCoopers. Retrieved from http://www.pwc.com/

20. Radchenko, O. (2012). Quality standards of bank clients' services as a factor of bank communication policy efficiency iç creasing. Nauka I Studia, 18(63), 18-23.

21. Reid, M. (2005). Performance Auditing of Integrated Marketing Communication (IMC) Actions and Outcomes. Journal of Advertising, 34(4), 41-54.

22. Reidenbach, R.R., Pitts, R.E. (1986). Bank Marketing: A Guide to Strategic Planning. Reston-Prentice Hall, Inc., 239 p.

23. Reidenbach, R., Moat, D., Pitts, R. (1986). The Impact of Marketing Operations on Bank Performance: A Structural Investigation. Journal of Bank Research, 18-27.

24. Samoylenko, M. (2008). The theory of probability. Kharkiv, 194 p.

25. Shen, G.C.C., Chiou, J.S., Hsiao, C.H., Wang, C.H., \& Li, H.N. (2016). Effective marketing communication via social networking site: The moderating role of the social tie. Journal of Business Research, 69(6), 2265-2270.

26. Tellis, G.J. (2006). Modeling marketing mix. Retrieved from http://www-bcf.usc.edu/ tellis/mix.pdf.

27. The Interactive Advertising Bureau. Retrieved from http://www.iab.net/.

28. World Federation of Advertisers. Retrieved from http://www.wfanet.org/en.

29. Young, A., Aitken, L. (2007). Profitable Marketing Communications: A Guide to Marketing Return of Investment. MPG Books Ltd., 224 p. 


\section{Appendix}

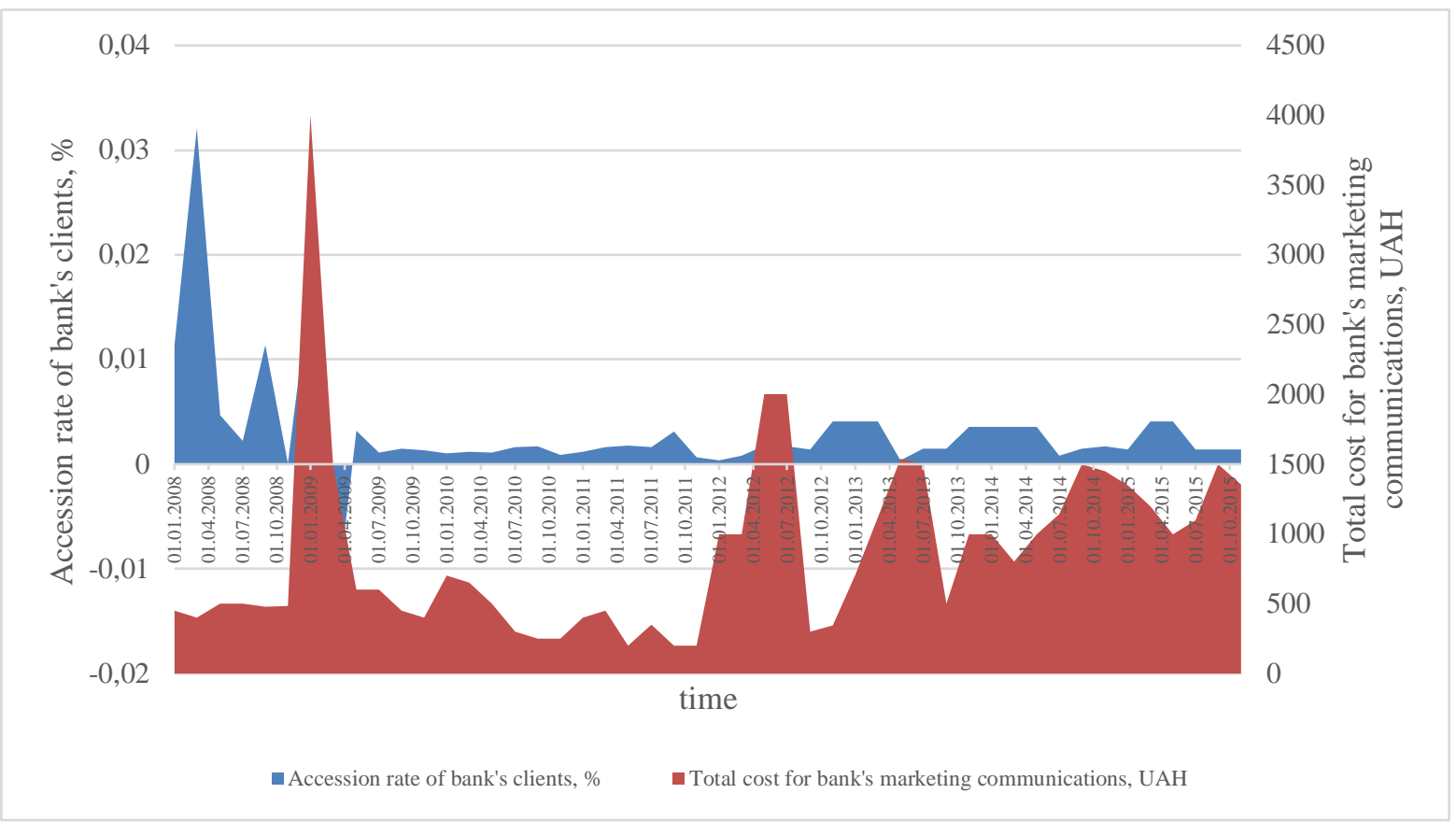

Figure 1. Correlation between total cost for bank's marketing communications and accession rate of bank's clients on the example of JSC “Oschadbank” (Sumy, Ukraine)

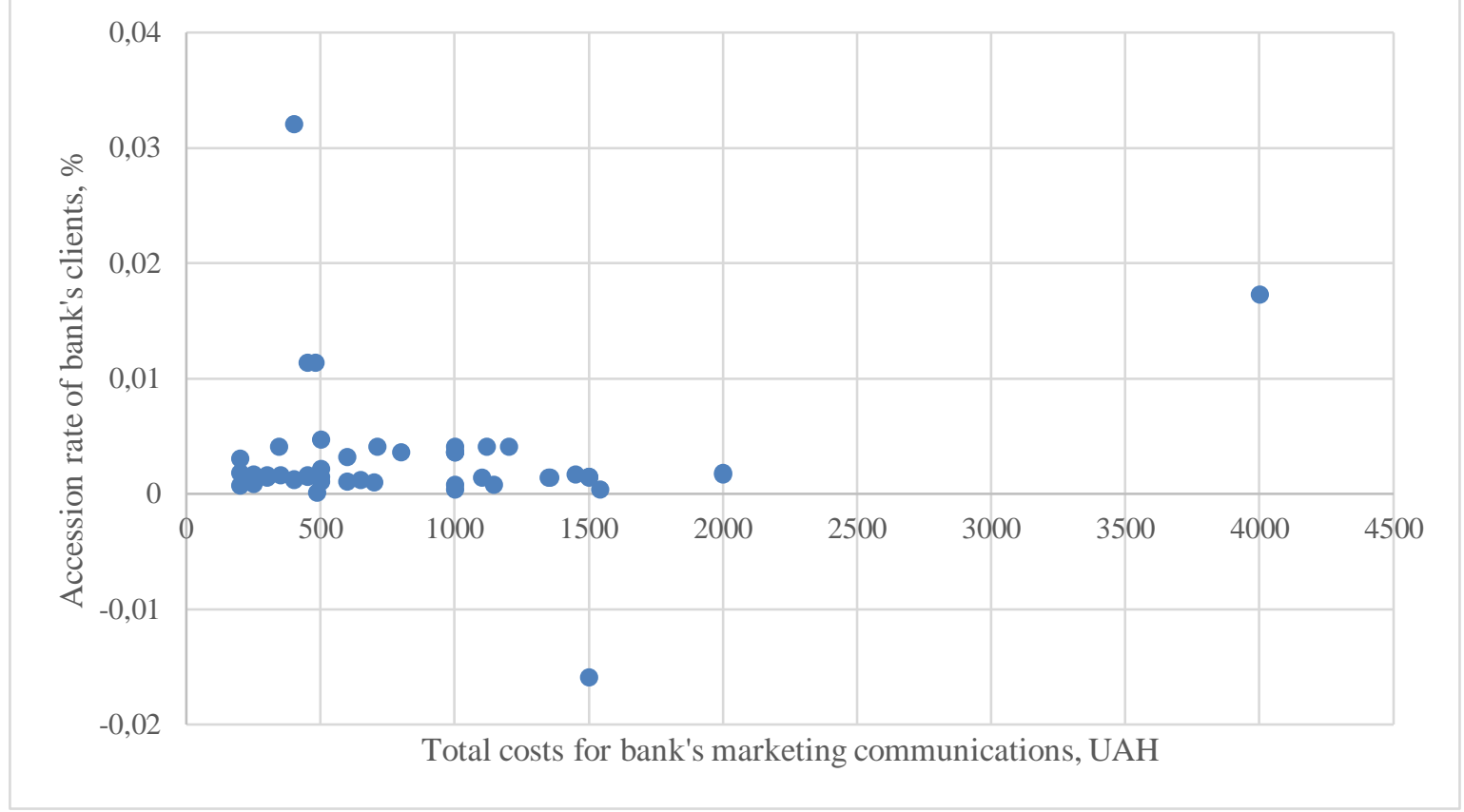

Figure 2. The graph analysing the decision the optimal combination of ration of increasing the bank's clients due to the bank's marketing communications on the example of JSC "Oschadbank" (Sumy, Ukraine) 